\title{
Applicability Analysis of Simulation Model of Metal Oxide Arrester and Experimental Study
}

\author{
Shoubin Liu ${ }^{1}$, Yapeng $\mathrm{Yao}^{2, *}$, Chongxin $\mathrm{Liu}^{2}$ and Jiantong $\mathrm{Zhu}^{3}$ \\ ${ }^{1}$ State Grid Yangquan Power Supply Company, Yangquan 045000, China; \\ ${ }^{2}$ State Key Laboratory of Electrical Insulation and Power Equipment, Xi'an Jiaotong University, Xi'an 710049, China; \\ ${ }^{3}$ Beijing RISECOMM Communication Technology Co., Ltd, Beijing 100050, China \\ ${ }^{*}$ Corresponding author
}

\begin{abstract}
The study on the simulation model of the metal oxide arrester (MOA) is of great significance to its production test and application. Simulation method is usually applied to MOA simulation test for some small and medium-sized enterprises with limited test conditions. The situation that there are a great wide variety of MOA models makes it more significant to study their applicability. The MOA simulation model research status was introduced in this paper, and three models, including IEEE model, Pinceti model and MWR model, were carried out by the Alternative Transient ProgramElectromagnetic Transient Program (ATP-EMTP), where the Heidler current source and the RLC discharge circuit were used to produce different impulse currents, including $8 / 20 \mu \mathrm{s}, 30 / 80 \mu \mathrm{s}$ and steep current with front time about $1 \mu \mathrm{s}$. Besides, the lightning impulse simulation of the whole arresters was experimentally researched under the nominal current. Then simulation results and experimental results were compared and analyzed according to the relative error of residual voltage and energy absorption. It is shown that the simulation waveform of the RLC discharge circuit is similar to the test waveform, which can effectively improve the problem of large relative error of the absorption energy, and the residual voltage simulation results of the three models are all good under $8 / 20 \mu$ s and $30 / 80 \mu$ s current. The IEEE model has shown good agreement in terms of the results of MOVs under steep current and the whole arresters under the nominal current. The difference between the two kinds of circuit design was analyzed, which can provide a reference for solving the problems in the current research, and improve work efficiency for testing institution.
\end{abstract}

Keywords-metal oxide arrester; ATP-EMTP; simulation model; impulse current generator; proof-test

\section{INTRODUCTION}

Metal oxide arresters show excellent electrical performance including high nonlinearity, fast response speed and great energy-absorption capacity, which are widely used as protective equipment against switching and lightning overvoltage in power electrical systems ${ }^{[1-5]}$. The core component of MOA is metal-oxide varistors, the ability of which in energy-absorption and overvoltage limitation determines the electrical characteristics. To ensure the accuracy of electromagnetic transient simulation and calculation, it is of great importance to study the applicability of MOA electrical model.
The simulation of the MOA model can be traced back to 1970 s, since then, many models have been proposed ${ }^{[6-14]}$. The nonlinear inductance model ${ }^{[6]}$ proposed by S. Tominaga(1979) can represent the dynamic characteristic for a narrow range of time to crest, where at least 20 voltage and current points as the conventional model are needed [7]. The nonlinear inductance model has the accuracy of about $1 \%$ error in calculations of steep front impulse. The model proposed by D. W. Durbak and adopted by the IEEE is more widely used. Since 1981, the working group 3.4.11 on Surge Arrester Modeling Techniques has been gathering data on the characteristics of MOAs. A series of studies have been carried out and it is shown that the model can give satisfactory results for discharge currents with a range of times to crest for $0.5 \mu$ s to $45 \mu \mathrm{s}{ }^{[8,9]}$. Since then, a variety of simplified models based on the IEEE model have been proposed successively ${ }^{[10-13]}$, such as Pinceti model (1999), Fernandez model(2001), P.Valsalal model(2011) and P-K model(2014). MWR(MOSA Wide-range) model(2017) proposed by Valdemir S. Brito was developed and validated based on MOSA electrical behavior in each one of the three operating regions of the zinc-oxide $(\mathrm{ZnO})$ surge arresters, and in a database composed of voltage and current waveforms measured from tests performed in twelve $\mathrm{ZnO}$ varistors having different physical dimensions and electrical characteristic from five different manufacturers. It was shown that most of the waveform simulation results (under $8 / 20 \mu$ s, $4 / 10 \mu$ s and $3 / 6 \mu \mathrm{s}$ ) were similar with the experimental data but the error was larger for the current impulse $1.5 / 26 \mu \mathrm{s}{ }^{[14]}$. Some models were analyzed and studied by He Yuwei ${ }^{[15]}$ and suggestion was put forward for reference.

The study of the simulation model has been mainly focused on MOVs, while the analysis of the whole lightning arrester is rarely made. Simulation method is usually applied to simulation test of the metal oxide arrester (MOA) for some small and medium-sized enterprises with limited test conditions. The situation that there are a great wide variety of MOA models makes it more significant to study their applicability. Based on the existing research, three models, including IEEE model, Pinceti model and MWR model, were carried out by the Alternative Transient Program-Electromagnetic Transient Program (ATP-EMTP), where the Heidler current source and the RLC discharge circuit were used to produce different impulse currents, including $8 / 20 \mu \mathrm{s}, 30 / 80 \mu$ s and steep current with front time about $1 \mu \mathrm{s}$. Besides, the lightning impulse simulation of the whole arresters was experimentally 
researched under the nominal current. The difference between the two kinds of circuit design was analyzed, which can provide a reference for solving the problems in the current research, and improve work efficiency for testing institution.

\section{Simulation MODEL}

\section{A. IEEE Model}

The IEEE model is put forward earlier and applied more widely. The model contains two nonlinear resistors and multiple linear components (see Figure I). The determination of these parameters requires comprehensive consideration of MOA electrical and structural characteristics.

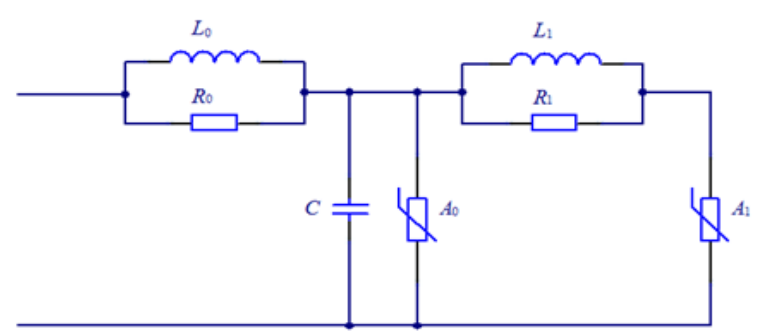

FIGURE I. IEEE MODEL

For this model the non-linear V-I characteristic of an arrester is represented with two sections of nonlinear resistance designated $A_{0}$ and $A_{1}$. The two sections are separated by an R-L filter for studying the change of the residual voltage under different impulse current. The resistor $R_{0}$ is used to avoid numerical oscillations when running the model with a digital program. The capacitance $C$ represents the external capacitance associated to the height of the arrester. And the starting values can be obtained through formulas that take into account both the electrical data, and the physical parameters.

$$
\begin{aligned}
& R_{0}=100 \frac{d}{n}(\Omega) \\
& R_{1}=65 \frac{d}{n}(\Omega) \\
& L_{0}=0.2 \frac{d}{n}(\mu \mathrm{H}) \\
& L_{1}=15 \frac{d}{n}(\mu \mathrm{H}) \\
& C=100 \frac{n}{d}(\mathrm{pF})
\end{aligned}
$$

$$
A_{i}=A_{i}^{*} \frac{U_{8 / 20}}{k}(i=0,1)(\mathrm{kV})
$$

Where $d$ is the estimated height of the arrester in meters; $n$ is the number of the parallel columns in MOA; $A_{i}{ }^{*}$ is referred to the data of W.G. 3.4.11 ${ }^{[8]} ; U_{8 / 20}$ is residual voltage at $10 \mathrm{kA}$ current surge with a $8 / 20 \mu$ s shape; $k$ is the adjustment parameter of nonlinear components.

How to identify the parameter of the model is the main problem and iterative correction is necessary to identify the parameters. But the study that the parameters influence on the simulation results through adjusting parameter provides a reference for further optimization.

\section{B. Pinceti Model}

Pinceti model is a simplified model, which derives from the IEEE model (see Figure II). The characteristics of nonlinear components adopt the IEEE model standard. For the linear components (inductors), new parameters identification standard is put forward [10, 16], without considering the physical characteristics of arresters.

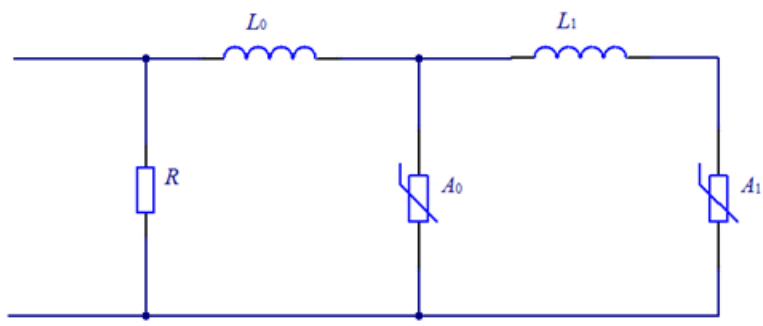

FIGURE II. PINCETI MODEL

$L_{0}=\frac{1}{12} \frac{U_{1 / T_{2}}-U_{8 / 20}}{U_{8 / 20}} U_{n}(\mu \mathrm{H})$

$$
L_{1}=\frac{1}{4} \frac{U_{1 / T_{2}}-U_{8 / 20}}{U_{8 / 20}} U_{n}(\mu \mathrm{H})
$$

Where $U_{\mathrm{n}}$ is the arrester rated voltage; $U_{1 / T 2}$ is residual voltage at $10 \mathrm{kA}$ current surge with a $1 / T_{2} \mu \mathrm{s}$ shape. The fast front current surge is $1 / 5 \mu \mathrm{s}$, and $T_{2}=5$ is taken in this paper.

$$
\begin{aligned}
& L_{0}=0.01 U_{n}(\mu \mathrm{H}) \\
& L_{1}=0.03 U_{n}(\mu \mathrm{H})
\end{aligned}
$$

When not all of the data to calculate the dynamic parameters are available, formula (9) - (10) can be beneficial. 


\section{MWR Model}

The MOA V-I characteristics can be divided into three regions to analyze ${ }^{[14]}$. In the region $\mathrm{I}$, the current density is lower than $0.1 \mathrm{~mA} / \mathrm{cm}^{2}$, the V-I characteristic is approximately linear, and exhibits dependence on temperature, as well as capacitive behavior. In the region II, MOA's main region, the degree of nonlinearity is determined by nonlinear region flatness; its electrical behavior is almost purely resistive. In the region III, high current or upturn region, the current density is larger than $10^{3} \mathrm{~A} / \mathrm{cm}^{2}$. The latest model, MWR model, is based on the analysis of the experimental data and the existing research.

In Figure III, the inductance $L$ represents the magnetic fields associated with the current that flows through the MOA; the capacitance $C$ represents the electric permittivity of the MOVs, important for modeling of the low current region; the resistances $R_{L}$ and $R_{C}$ are used to avoid possible numerical oscillations from some simulation software.

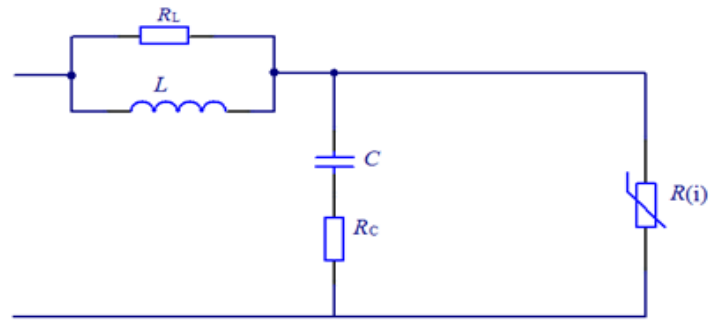

FIGURE III. MWR MODEL

$$
\begin{gathered}
L=\frac{h}{n}(\mu \mathrm{H}) \\
R_{L}=\frac{8 \times L}{\Delta t}(\Omega) \\
R_{C}=\frac{0.15 \times \Delta t}{2 C}(\Omega)
\end{gathered}
$$

\section{TEST MEASUREMENT}

\section{A. Test Conditions}

To study the applicability of the above models, we choose different MOAs and MOVs produced by different manufacturers. The test is carried out in Quality Inspection and Test Center for Equipment of Electric Power, China Electric Power Research Institute. The sample parameters are shown in Table I and Table II.
TABLE I. BASIC PARAMETERS OF MOVS

\begin{tabular}{|c|c|c|c|c|c|}
\hline SAMPLE & A1 & A2 & A3 & A4 & A5 \\
\hline "Height $/ \mathrm{mm}$ & 1263 & 326 & 265 & 1370 & 370 \\
\hline Dimension $/ \mathrm{mm}$ & $60 \times 25$ & $53 \times 22$ & $35 \times 22$ & $53 \times 22$ & $35 \times 25$ \\
\hline $\begin{array}{l}\text { Nominal discharge } \\
\text { current } / \mathrm{kA}\end{array}$ & 10 & 5 & 5 & 10 & 5 \\
\hline Rated voltage $/ \mathrm{kV}$ & 108 & 17 & 17 & 108 & 34 \\
\hline $\begin{array}{c}\text { Residual } \\
\text { voltage }(8 / 20 \mu \mathrm{s}) / \mathrm{kV}\end{array}$ & 250.8 & 39.1 & 46.1 & 268.8 & 81.57 \\
\hline $\begin{array}{c}\text { Line discharge } \\
\text { class }\end{array}$ & 3 & / & I & 2 & / \\
\hline MOA Type & $\begin{array}{l}110 \mathrm{kV} \\
\text { power } \\
\text { station }\end{array}$ & $\begin{array}{l}10 \mathrm{kV} \\
\text { power } \\
\text { station }\end{array}$ & $\begin{array}{c}10 \mathrm{kV} \\
\text { power } \\
\text { distribution }\end{array}$ & $\begin{array}{l}110 \mathrm{kV} \\
\text { power } \\
\text { station }\end{array}$ & $\begin{array}{l}20 \mathrm{kV} \\
\text { power } \\
\text { station }\end{array}$ \\
\hline
\end{tabular}

\begin{tabular}{cccc}
\hline SAMPLE & S1 & S2 & S3 \\
\hline \hline $\begin{array}{c}\text { Dimension } \\
\text { (diameter } \times \text { height)/mm }\end{array}$ & $31 \times 24$ & $42 \times 24$ & $62 \times 22$ \\
Nominal discharge & & & \\
current/kA & 5 & 10 & 10 \\
Rated voltage/kV & 3.66 & 3.67 & 3.42 \\
Residual voltage $(8 / 20 \mu \mathrm{s}) / \mathrm{kV}$ & 8.92 & 8.85 & 8.04 \\
Residual voltage & 9.9 & 10.02 & 9.16 \\
(steep front impulse)/kV & $/$ & 2 & 3 \\
Line discharge class & $20 \mathrm{kV}$ & $10 \mathrm{kV}$ & $220 \mathrm{kV}$ \\
& power & power & power \\
MOA Type & station & distribution & station \\
\hline
\end{tabular}

TABLE II. BASIC PARAMETERS OF MOAS

B. Test Methods and Results

Comply with GB 11032-2010 "Metal-oxide surge arresters without gaps for A.C. systems" during the test ${ }^{[17]}$, and MOVs (Table 1) were subjected to impulse currents with the following wave shapes: $8 / 20 \mu \mathrm{s}, 30 / 80 \mu$ s and steep current with front time about $1 \mu \mathrm{s}$. The residual voltage and energy absorption of MOVs under the corresponding impulse current were measured

\begin{tabular}{|c|c|c|c|c|}
\hline \multicolumn{2}{|c|}{ SAMPLE } & \multirow{2}{*}{$\begin{array}{c}\text { S1 } \\
8.92\end{array}$} & \multirow{2}{*}{$\begin{array}{l}\text { S2 } \\
8.85\end{array}$} & \multirow{2}{*}{$\begin{array}{c}\text { S3 } \\
8.04\end{array}$} \\
\hline $8 / 20 \mu$ s under & $\begin{array}{c}\text { Residual } \\
\text { voltage } / \mathrm{kV}\end{array}$ & & & \\
\hline $\begin{array}{l}\text { nominal } \\
\text { discharge current }\end{array}$ & $\begin{array}{c}\text { Energy } \\
\text { absorption/kJ }\end{array}$ & 0.72 & 1.35 & 1.22 \\
\hline \multirow{2}{*}{$\begin{array}{l}30 / 80 \mu \text { s under } \\
500 \mathrm{~A} \text { current }\end{array}$} & $\begin{array}{c}\text { Residual } \\
\text { voltage } / \mathrm{kV}\end{array}$ & 7.26 & 6.93 & 6.43 \\
\hline & $\begin{array}{c}\text { Energy } \\
\text { absorption } / \mathrm{kJ}\end{array}$ & 0.304 & 0.3 & 0.268 \\
\hline \multirow{2}{*}{$\begin{array}{c}1 \mu \text { s under } \\
\text { nominal } \\
\text { discharge current }\end{array}$} & $\begin{array}{c}\text { Residual } \\
\text { voltage } / \mathrm{kV}\end{array}$ & 9.9 & 10.02 & 9.16 \\
\hline & $\begin{array}{c}\text { Energy } \\
\text { absorption } / \mathrm{kJ}\end{array}$ & 0.286 & 0.48 & 0.456 \\
\hline \multicolumn{2}{|c|}{$U_{1 \mathrm{~mA} \cdot \mathrm{DC}} / \mathrm{kV}$} & 5.33 & 5.18 & 4.96 \\
\hline
\end{tabular}
and recorded in Table III.

TABLE III. THE EXPERIMENTALLY MEASURED RESULTS OF MOVS

The residual voltage values can be obtained easily, while energy absorption values in the test $\left(E_{\mathrm{m}}\right)$ and simulation $\left(E_{\mathrm{s}}\right)$ could be calculated using (14).

$$
E=\int_{0}^{t} u(t) \cdot i(t) d t
$$

Then, the relative errors $\left(E_{\mathrm{u}}, \mathrm{E}_{\mathrm{e}}\right)$ were calculated in accordance with (15) and (16), respectively. 


$$
\begin{gathered}
E_{u}=\frac{U_{s}-U_{m}}{U_{m}} \cdot 100 \% \\
E_{e}=\frac{E_{s}-E_{m}}{E_{m}} \cdot 100 \%
\end{gathered}
$$

\section{Simulation CALCUlation AND ERROR ANALYSIS}

According to the actual sample parameters, the parameters of each simulation model were calculated, and simulations with above models were performed in the ATP-EMTP software. The widely used Heidler current source was selected.

As the previous studies were shown, when using Heidler source, the energy absorption error was relatively large. In this paper, the RLC discharge circuit is proposed and used, and the simulation results will be more accurate. According to the actual parameters of the impulse current generator, the model of RLC discharge circuit was designed.

The simulation performance can be optimized through adjusting the value of nonlinear resistance $\left(A_{0}, A_{1}\right)$ in IEEE model. In this paper, the impact of the adjustment parameter $\mathrm{k}$ is analyzed. Figure 4 is the curve of the relative error between the $\mathrm{k}$ value and the residual voltage under the nominal current of the sample S3, A1 and A3.

From Figure IV, we can see that the residual voltage error is relatively small when the value of adjustment parameter $k$ is in the range of 1.55-1.75. Therefore, choosing the $k$ value appropriately can make the IEEE model perform much better. Then, the similar operation is implemented under other waveforms.

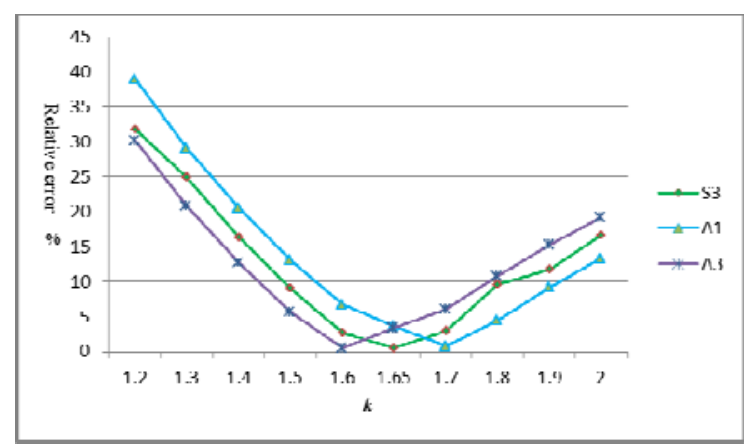

FIGURE IV. THE CURVE OF $k$ TO THE RELATIVE ERROR OF RESIDUAL VOLTAGES ( $8 / 20 \mu \mathrm{s}$ IN S3, A1, A3)

Figure $\mathrm{V}$ shows the test and simulation waveforms of the sample S3 in three kinds of wave shapes, among which (a)-(c) are the experimental waveforms, and (d)-(i) mean the simulation waveforms of the residual voltage and energy absorption with the three above mentioned models under different sources (Heidler source, RLC discharge circuit), respectively.

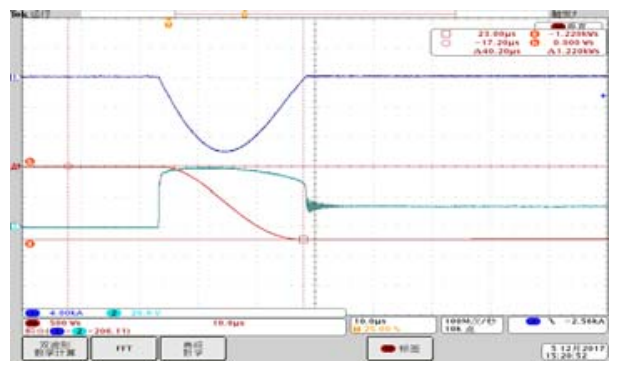

(a) $8 / 20 \mu$ s test waveform

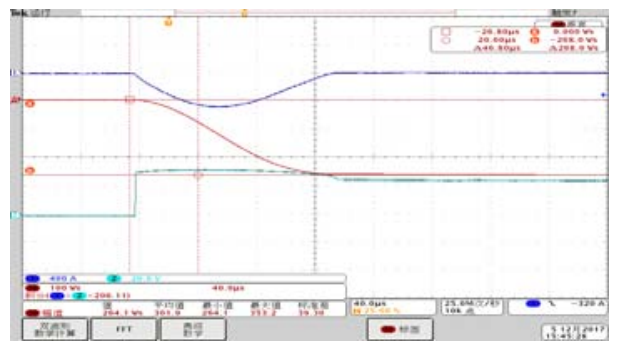

(b) $30 / 80 \mu$ s test waveform

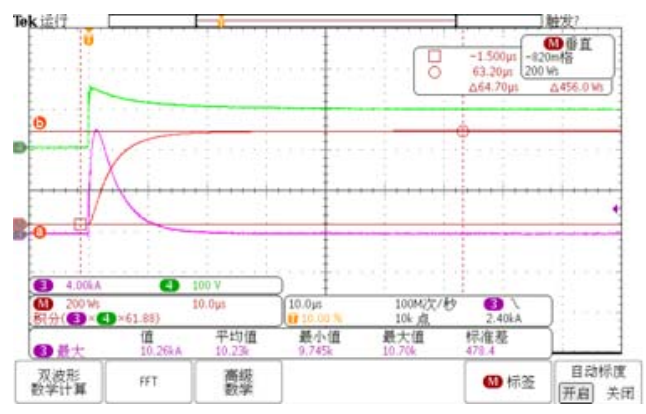

(c) $1 / 5 \mu$ s test waveform

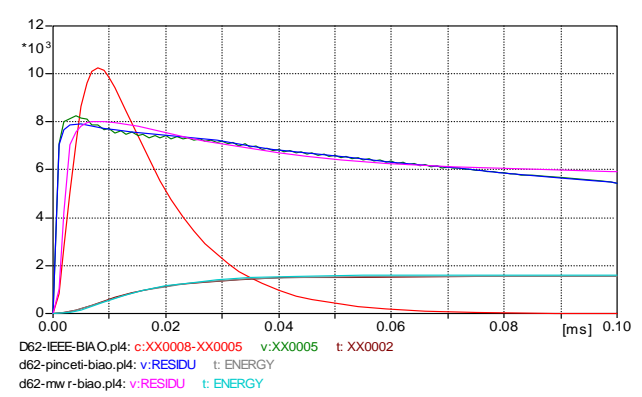

(d) $8 / 20 \mu$ s simulation waveform (Heidler)

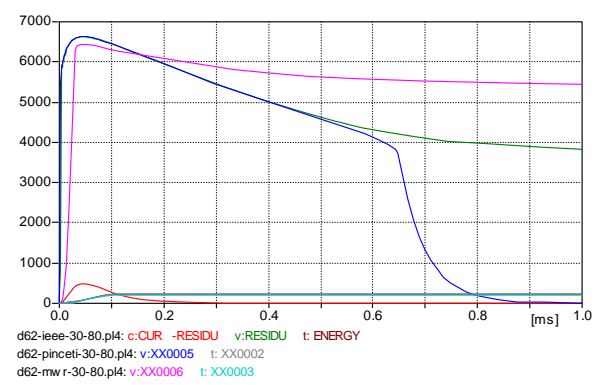

(e) $30 / 80 \mu$ s simulation waveform (Heidler) 


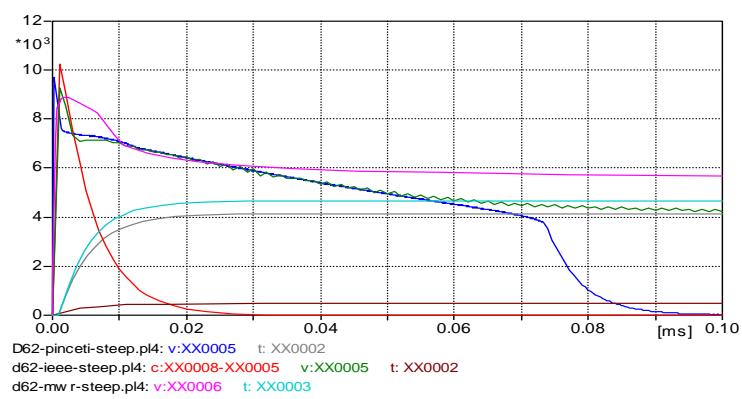

(f) $1 / 5 \mu$ s simulation waveform (Heidler)

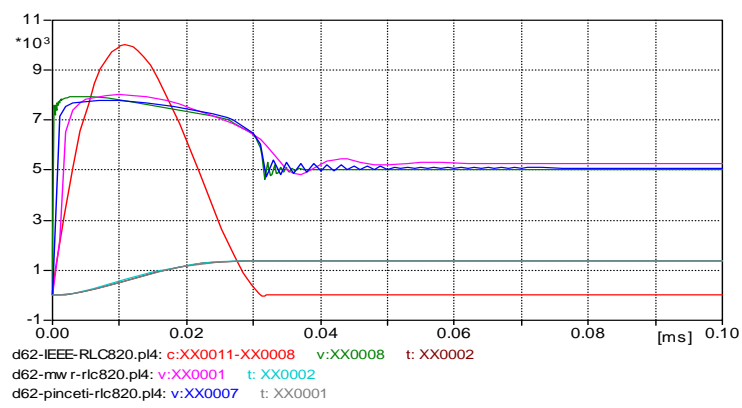

(g) $8 / 20 \mu \mathrm{s}$ simulation waveform (RLC)

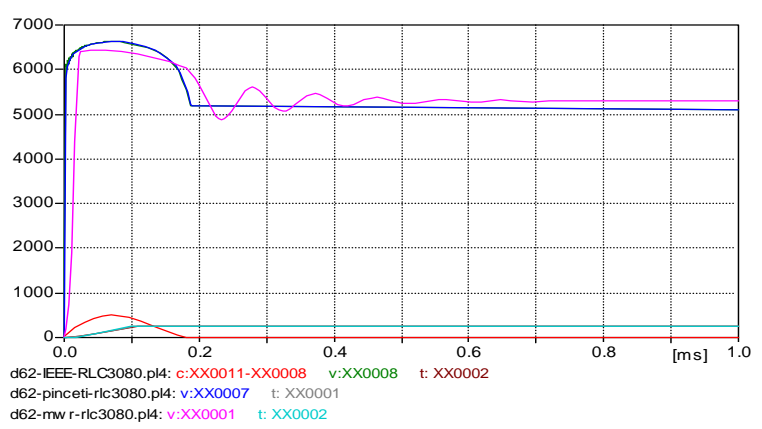

(h) $30 / 80 \mu \mathrm{s}$ simulation waveform (RLC)

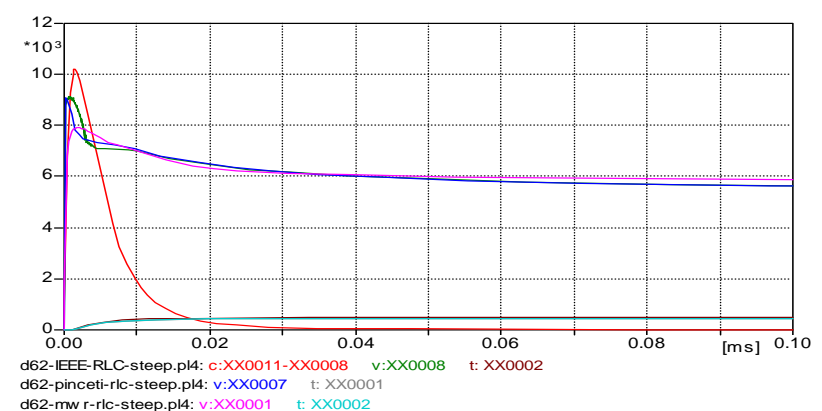

(i) $1 / 5 \mu$ s simulation waveform (RLC)

FIGURE V. THE MEASURED AND SIMULATION WAVEFORMS IN S3 UNDER DIFFERENT IMPULSE CURRENT $(8 / 20 \mu \mathrm{s}, 30 / 80 \mu \mathrm{s}$ and $1 / 5 \mu \mathrm{s})$

It can be clearly seen from Figure $\mathrm{V}$ that the simulation results of two different current source circuits are similar, but the simulated waveform (g) - (i) obtained from the RLC discharge circuit is closer to the test waveform (a) - (c).
In order to make the simulation results of each model more intuitive, Figure VI is the relative error of the residual voltage and the energy absorption of the three models under different waveforms.

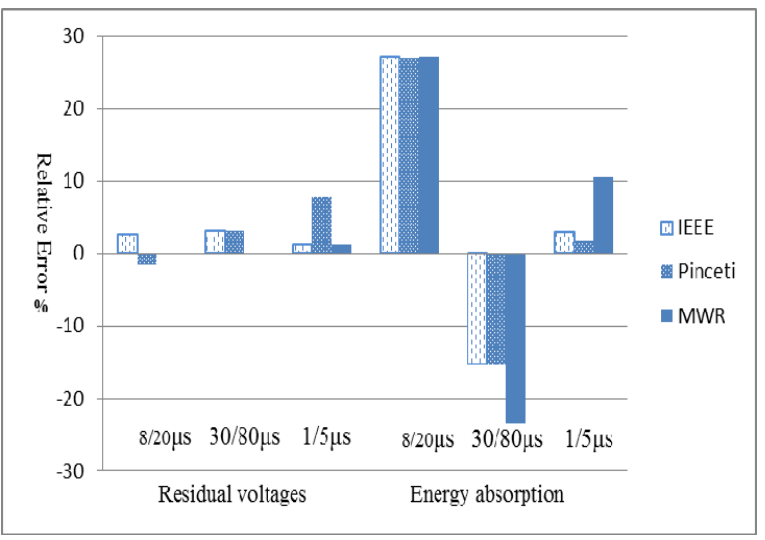

(a) Heidler Source

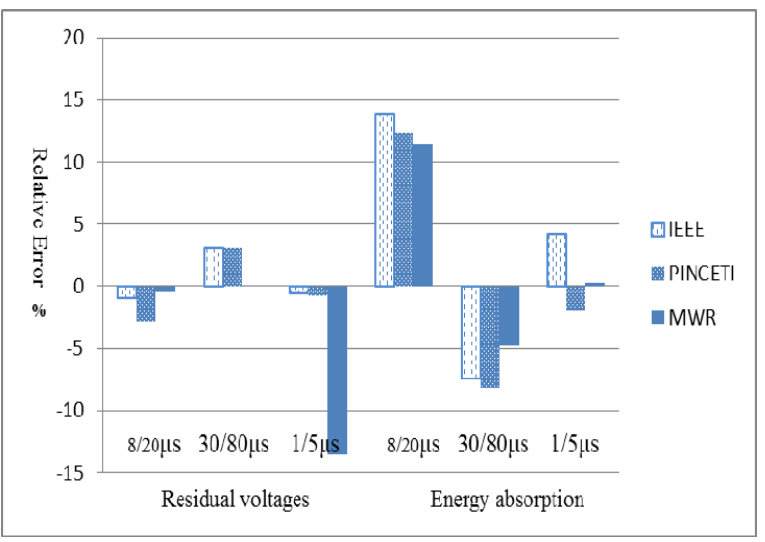

(b) RLC Discharge Circuit

FIGURE VI. THE RELATIVE ERROR OF RESIDUAL VOLTAGES AND ENERGY ABSORPTION IN S3

As the Heidler current source simulation results (see Figure VI (a)) show, the relative error of the residual voltage was small for these three models, among which the residual voltage relative error of IEEE model and MWR model under three different impulse currents are less than 3.2\%, MWR model error is smaller and less than $1 \%$ in $8 / 20 \mu$ s and $30 / 80 \mu \mathrm{s}$ impulse current, and only $1.2 \%$ in the steep wave impulse current; for Pinceti model, the relative error in $8 / 20 \mu$ s and $30 / 80 \mu$ s impulse current are less than $\pm 3.2 \%$, and in the steep wave impulse current error is $7.8 \%$; while the error of the energy absorption is relatively large, which are positive and in excess of $25 \%$ in $8 / 20 \mu$ s impulse current; steep wave impulse current simulation results are relatively small; the results of the measured test waveform parameters are consistent with the standard specification, which meet the needs of actual project. The accuracy of evaluating energy absorption is mainly affected by the waveform precision of impulse current and residual voltage. The current waveform difference between the simulation and the test at the end of the wave leads to the cumulative increase of the error in the calculation of the absorption energy (14). The reason that the error of the energy 
absorption is relatively large is that Heidler current source is used. The waveform parameters (wave front time, tail time) can be adjusted directly according to the simulation requirements, and the study of the discharge circuit is not carried out.

For further verification, the RLC discharge circuit simulation error results is shown in Figure VI (b), the residual voltage error of the three models in $8 / 20 \mu$ s and $30 / 80 \mu \mathrm{s}$ impulse current is small, among which the residual voltage relative error of IEEE model and Pinceti model in the steep wave impulse current is less than $\pm 1 \%$, while the error of MWR model in the steep wave impulse current is relatively large, which is consistent as depicted in [14]; in evaluating energy absorption, the results of the three models are obviously improved compared to the results of Heidler current source.
The RLC discharge circuit simulation results of MOVs are shown in Table IV. For the residual voltage, the relative error of the three models are smaller in $8 / 20 \mu$ s and $30 / 80 \mu$ s impulse current, among which the residual voltage error of IEEE model can be maintained in the range of $\pm 6 \%$, maximum error $-6.61 \%$ in Pinceti model, the relative error is less than $\pm 4 \%$ in MWR model, and the simulation result is more accurate; in the steep wave impulse current, IEEE model simulation results are accurate, while the performance of other two models is not stable, which is relevant to the variety of the sample.

The results of MOVs' energy absorption error are shown in Table V. The value of energy absorption error is decreased appreciably compared with using the Heidler current source.

TABLE IV. RELATIVE ERROR OF RESIDUAL VOLTAGES (MOVS WITH RLC CIRCUIT)

\begin{tabular}{cccccccccc}
\hline \multirow{2}{*}{ MODEL } & \multicolumn{3}{c}{$\mathbf{8} / \mathbf{2 0} \boldsymbol{\mu} \mathbf{s}$} & \multicolumn{3}{c}{$\mathbf{3 0 / 8 0} \boldsymbol{\mu} \mathbf{s}$} & $\mathbf{1 / 5} \boldsymbol{\mu}$ \\
& $\mathbf{S 1}$ & $\mathbf{S 2}$ & $\mathbf{S 3}$ & $\mathbf{S 1}$ & $\mathbf{S 2}$ & $\mathbf{S 3}$ & $\mathbf{S 1}$ & $\mathbf{S 2}$ & $\mathbf{S 3}$ \\
\hline \hline IEEE & -5.72 & -0.9 & -0.99 & 1.38 & 5.34 & 3.11 & -5.66 & -0.79 & -0.55 \\
Pinceti & -6.61 & -2.82 & -2.87 & 1.24 & 5.19 & 3.11 & -11.8 & -1.19 & -0.76 \\
MWR & 3.92 & -0.23 & -0.37 & 1.65 & 0.87 & 0 & 2.12 & -11.3 & -13.5 \\
\hline
\end{tabular}

TABLE V. RELATIVE ERROR OF ENERGY ABSORPTION (MOVS WITH RLC CIRCUIT)

\begin{tabular}{cccccccccc}
\hline \multirow{2}{*}{ MODEL } & \multicolumn{3}{c}{$\mathbf{8} / \mathbf{2 0} \boldsymbol{\mu} \mathbf{s}$} & \multicolumn{4}{c}{$\mathbf{3 0 / 8 0} \boldsymbol{\mu} \mathbf{3}$} & $\mathbf{1} \mathbf{5} \boldsymbol{\mu \mathbf { S }}$ \\
\cline { 2 - 9 } & $\mathbf{S 1}$ & $\mathbf{S 2}$ & $\mathbf{S 3}$ & $\mathbf{S 1}$ & $\mathbf{S 2}$ & $\mathbf{S 3}$ & $\mathbf{S 1}$ & $\mathbf{S 2}$ & $\mathbf{S 3}$ \\
\hline \hline IEEE & 9.72 & 14.1 & 13.9 & -7.24 & -8.3 & -7.46 & -1.75 & 9.38 & 4.17 \\
Pinceti & 8.33 & 12.6 & 12.3 & -8.88 & -9.67 & -8.21 & -4.55 & 4.58 & -1.97 \\
MWR & 11.1 & 14.8 & 11.5 & -9.21 & -14.7 & -4.85 & 11.2 & 10.8 & 0.22 \\
\hline
\end{tabular}

Take waveform and relative error of the residual voltage and energy absorption into consideration and analyze the simulation result. For MOVs simulation, the result of RLC discharge circuit is similar to experiment data. With the further analysis, the relative error of residual voltage with the three models is smaller in $8 / 20 \mu$ s and $30 / 80 \mu$ s impulse current, and the absorption energy error is obviously improved than that of Heidler; but due to the influence of the MOVs' nonlinear characteristics on the loop parameters, these parameters need to be adjusted according to the sample. While the Heidler current source as a function package module, the output current waveform is not influenced by load, but there are some subtle differences in the wave tail between the actual test waveform and the simulation, thus affecting the accuracy of energy absorption value. From the above simulation experiments, it is found that the two circuit designs have little influence on the residual voltage. When the absorption of energy is not considered, the Heidler current source is easy to operate and it only needs to modify the waveform parameters.

The simulation results of the whole arrester are shown in Table VI. The residual voltage error obtained by three models is smaller; the simulation results of IEEE model are more accurate, and the maximum error is less than $\pm 2 \%$. For $110 \mathrm{kV}$ arrester (A1, A4), simulation results of Pinceti model and MWR model are smaller, and the MWR model error is less than $1 \%$; for the rest of the sample, simulation error is less than $\pm 7 \%$.

TABLE VI. THE SIMULATED RESIDUAL VOLTAGES OF MOAS

\begin{tabular}{cccccc}
\hline MODEL & A1 & A2 & A3 & A4 & A5 \\
\hline \hline Test value & 250.8 & 39.1 & 46.1 & 268.8 & 81.57 \\
IEEE & 252.7 & 39.94 & 46.6 & 271.1 & 79.93 \\
Pinceti & 245.3 & 36.63 & 43.3 & 262.48 & 76.39 \\
MWR & 250.04 & 36.33 & 42.84 & 268 & 75.8 \\
\hline
\end{tabular}

\section{CONCLUSION}

In this paper, MOVs having different physical dimensions and electrical characteristic and MOAs from different manufacturers are simulated, respectively. The waveforms of the voltages and currents supplied by the above three models were compared with the lab tests results.

- In IEEE model, the model simulation performance can be optimized by adjusting the parameter $\mathrm{k}$ value, and the relative error of the residual voltage is smaller when the value of adjustment parameter $\mathrm{k}$ is in the range of 1.55-1.75.

- In MOVs simulation, RLC discharge circuit was applied, and the waveforms of the voltages or currents supplied by the above three model were similar to the lab tests results. The relative error of the residual voltage is small for these three models in $8 / 20 \mu$ s and $30 / 80 \mu$ s impulse current, among which MWR model performs better, and IEEE model comes next. In the steep wave impulse current, IEEE model simulation results are accurate, while the performance of other 
two models is not stable, which is relevant to the variety of the sample. When the absorption of energy is not taken into account, the Heidler current source can be adopted with applicable simulation model.

- The whole MOA is simulated, and the relative error of residual voltage obtained by the three models is relatively small. The simulation results of IEEE model are more accurate. The simulation results for $110 \mathrm{kV}$ arresters (A1, A4), Pinceti model and MWR model are better.

\section{ACKNOWLEDGMENT}

The measurement and record of experiment is completed under the support of the Quality Inspection and Test Center for Equipment of Electric Power, China Electric Power Research Institute, and I would like to express my sincere appreciation and gratitude to him (her).

\section{REFERENCES}

[1] XIONG Taichang, "Electrical surge arrester," Beijing: China Water \& Power Press, 2013.

[2] HE Yunhu, "Applications of MOA in Power System," Electric Power Automation Eguipment, vol. 21, pp. 51-54, June 2001.

[3] LI Pengfei, ZHANG Chunlong, LÜ Dongbo, YANG Zhongjiang, ZHAO Jun, "Failure modes of metal oxide arrestor under the multi-pulse lightning surges," High Voltage Engineering, vol. 43, pp. 3792-3799, November,2017.

[4] HE Jinliang, LIU Jun, HU Jun, LONG Wangcheng, "Development of $\mathrm{ZnO}$ varistors in metal oxide arrestors utilized in Ultra high voltage systems," High Voltage Engineering, vol. 37, pp. 634-643, March 2011.

[5] CHEN Jie, GUO Jie, QIU Aici, "Experimental investigation on the response characteristics of metal oxide varistors under very fast transient overvoltage," Proceedings of the CSEE, vol. 35, pp. 3436-3442, September 2015.

[6] S. Tominaga, K. Azumi, Y. Shibuya, M. Imataki, "Protective Performance of Metal Oxide Surge Arrester Based on the Dynamic V-I Characteristics," IEEE Transactions on Power Apparatus \& Systems, vol. PAS-98, pp. 1860-1871, November 1979.

[7] I. Kim, T. Funabashi, H. Sasaki, T. Hagiwara, M. Kobayashi, "Study of $\mathrm{ZnO}$ arrester model for steep front wave," IEEE Transactions on Power Delivery, vol. 11, pp. 834-841, April 1996.

[8] IEEE Working Group 3.4.11, "Modeling of metal oxide surge arresters," IEEE Transactions on Power Delivery, vol. 7, pp. 302-309, January 1992

[9] A. Goudarzi, H. Mohseni, "Accuracy evaluation of IEEE model for distribution class metal oxide surge arrester,"//Proceedings of the 39th International Universities Power Engineering Conference. Bristol, UK: IEEE, 2004, pp. 179-182.

[10] P. Pinceti, M. Giannettoni, "A simplified model for zinc oxide surge arresters," IEEE Transactions on Power Delivery, vol. 14, pp. 393-398, April 1999.

[11] F. Fernández, R. Díaz, "Metal oxide surge arrester model for fast transient simulations," Electric Power Components \& Systems, vol. 39,2001, pp. 696-712.

[12] P. Valsalal, S. Usa, K. Udayakumar, "Importance of Capacitance on Metal Oxide Arrester Block Model for VFTO Applications," IEEE Transactions on Power Delivery, vol. 26, 2011, pp. 1294-1295.

[13] P. Unahalekhaka, "Simplified modeling of metal oxide surge arresters," Energy Procedia, vol. 56, 2014, pp. 92-101.

[14] V. S. Brito, G. R. S. Lira, E. G. Costa, M. J. A. Maia, "A wide-range model for metal-oxide surge arrester," IEEE Transactions on Power Delivery, 2017, PP(99): 1-1.

[15] HE Yuwei, SI Wenrong, WEI Bengang, XIA Hailiang, FU Zhengcai, "Accuracy analysis of metal-oxide arrester simulation models considering the energy absorption estimation under impulse currents with different steepness," Proceedings of the CSEE, vol. 37, pp. 30193027, May 2017.

[16] M. C. Magro, M. Giannettoni, P. Pinceti, "Validation of $\mathrm{ZnO}$ surge arresters model for overvoltage studies," IEEE Transactions on Power Delivery, vol. 19, pp. 1692-1695, October 2004.

[17] General Administration of Quality Supervision, Inspection and Quarantine of the People's Republic of China, Standardization Administration of the People's Republic of China. GB 11032-2010 Metal-oxide surge arresters without gaps for A.C. systems. Beijing: Standards Press of China, 2011 